\title{
Barrett's oesophagus: epidemiology comes up with a surprise
}

\section{R C Heading}

\section{Although the risk of oesophageal adenocarcinoma is increased, this cancer is an uncommon cause of death in patients with Barrett's oesophagus}

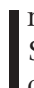
a Gut Commentary in 1997 Spechler ${ }^{1}$ observed that neither the definition nor the pathogenesis of Barrett's oesophagus were as straightforward as they had seemed only a few years earlier. Today, it looks as if oesophagologists need recourse to the black arts of journalistic spin if recent research on Barrett's is to be portrayed as bringing clarity to the subject, because in truth it has not had much success in resolving the major uncertainties about pathogenesis, clinical significance, and optimum patient management. Regrettably, we are still unable to answer very many important scientific and practical questions. For example, why do some patients with gastro-oesophageal reflux disease (GORD) develop Barrett's whereas others do not? What determines the length of the columnar segment? Why does it not lengthen with time despite continuing reflux? Is Barrett's the important precursor of oesophageal adenocarcinoma or is severe reflux the real risk factor irrespective of overt metaplasia of the epithelium? Is endoscopic surveillance of Barrett's oesophagus an essential part of good clinica practice or is it a waste of time and money? This is not a full list of the major questions, but it will serve as a start.

The paper by Anderson and colleagues $^{2}$ in this issue of Gut [see page 1081] confirms an observation previously made by others, ${ }^{3}{ }^{4}$ namely that although the risk of oesophageal adenocarcinoma is increased (about sixfold), this cancer is actually an uncommon cause of death in patients with Barrett's oesophagus. From this, it follows that we may expect mortality in Barrett's oesophagus patients to be similar to that in a matched control population. Anderson et al have taken the observations further however by conducting their study on a population basis and they have therefore been able to show that overall mortality in Barrett's oesophagus is virtually the same as mortality in the population at large. No support is given to an earlier suggestion ${ }^{3}$ that Barrett's oesophagus patients have an increased risk of death from cardiorespiratory disease: indeed, an unexpected finding was a reduction of approximately $50 \%$ in the risk of death from stroke in Barrett's patients.

Wholly unexpected findings are among the most exciting outcomes of research. Sometimes such findings are not replicated in subsequent studies; sometimes they initiate a truly important new approach to a subject. As far as this observation on stroke is concerned, the cautious investigator will approach the finding with a little scepticism. It certainly needs confirmation before we should accept it as fact. Nevertheless, the authors' suggested explanation is intriguing, namely that GORD (and the predisposition to Barrett's ) may be associated with low vascular tone, thus with low blood pressure and so a reduced occurrence of stroke. Abnormalities of cardiovascular autonomic function have been demonstrated in GORD, ${ }^{5}$ so there is some plausibility to the suggestion. If the authors' explanation is valid, new treatments for GORD that target neural control of the lower oesophageal sphincter and the frequency of its transient relaxations will in future need to be checked to ensure they do not inadvertently normalise low vascular tone and thereby increase the risk of stroke in these patients.

Population based epidemiological studies such as the one Anderson and colleagues $^{2}$ have conducted must often contend with the problem that it is difficult to apply tight diagnostic criteria to the condition being studied if any data at all are to be obtained. Diagnostic consistency in Barrett's oesophagus is notoriously difficult in the best of circumstances, ${ }^{7}$ but in this instance even the conventional diagnostic criteria for Barrett's oesophagus-that is, an endoscopist's diagnosis of Barrett's supported by appropriate histopathology-have not been used. In consequence, the conclusions of the study are necessarily weakened. However, the fact that the main conclusions are at least as powerfully demonstrated when only patients with intestinal metaplasia were examined goes some way to diminish reservations. Just as important however and certainly worthy of commendation is the authors' success in establishing the Northern Ireland Barrett's Register, enabling data to be gathered from the whole Northern Ireland population. In the future, there will no doubt be progressive improvement in the rigour and consistency of diagnostic criteria needed for inclusion of patients in the Register, such that an invaluable accurate database is created.

Epidemiological studies would seem to have much to contribute in resolving some of the issues surrounding Barrett's oesophagus that we have come to recognise in the last 10 years or so. For example, we still do not really know its prevalence. In the USA, Mayo clinic data have suggested a prevalence of 376 per $100000^{8}$ and that the condition is now recognised in approximately $20 \%$ of individuals who have it. ${ }^{9}$ In the UK, recent data show that only $14 \%$ of patients presenting with oesophageal adenocarcinoma are previously known to have Barrett's. ${ }^{10}$ Thus it is clear that most individuals who have Barrett's oesophagus go undiagnosed. This may be unimportant for many research purposes but could be a problem if individuals in whom the Barrett's diagnosis has been made are unrepresentative of the whole group with Barrett's. Worryingly, this may be true so far as the cancer risk is concerned. On average, Barrett's oesophagus probably develops 10-20 years before it is diagnosed but the average age of individuals newly diagnosed with Barrett's is only marginally lower than the average age of patients diagnosed with Barrett's cancer. ${ }^{11}$ Does this mean that individuals in whom Barrett's oesophagus has been diagnosed are less likely to develop cancer than those in whom the condition goes unrecognised? Such questions have direct clinical relevance as well as public health significance and population based epidemiology looks to be the only way the much needed quantitative information about the condition and its natural history can be gained.

Gut 2003;52:1079-1080

\section{Author's affiliation}

R C Heading, Centre for Liver and Digestive Disorders, Royal Infirmary, Edinburgh, UK; r.heading@ed.ac.uk

\section{REFERENCES}

1 Spechler SJ. The columnar lined oesophagus: a riddle wrapped in a mystery inside an enigma. Gut 1997:41:710-1.

2 Anderson LA, Murray LJ, Murphy SJ, et al. Mortality in Barrett's oesophagus: results from a population based study. Gut 2003;52: 1081-4

3 Van der Burgh A, Dees J, Hop WCJ, et al. Oesophageal cancer is an uncommon cause of death in patients with Barrett's oesophagus. Gut 1996;39:5-8.

4 Macdonald CE, Wicks AC, Playford RJ. Final results from 10 year cohort of patients undergoing surveillance for Barrett's 
oesophagus: observational study. BM 2000;321:1252-5.

5 Chakraborty TK, Ogilvie AL, Heading RC, et al. Abnormal cardiovascular reflexes in patients with gastro-oesophageal reflux. Gut 1989;30:46-9

6 Cunningham KM, Horowitz M, Riddell PS, et al. Relations among autonomic nerve dysfunction, oesophageal motility and gastric emptying in gastro-oesophageal reflux disease. Gut 1991;32:1436-40.
7 Kim SL, Waring JP, Spechler SJ, et al. Diagnostic inconsistencies in Barrett's esophagus. Gastroenterology 1994; 107:945-9.

8 Cameron AJ, Zinsmeister AR, Ballard DJ, et al. Prevalence of columnar-lined (Barrett's) esophagus. Comparison of population-based clinical and autopsy findings.

Gastroenterology 1990:99:918-22.

9 Conio M, Cameron AJ, Romero Y, et al. Secular trends in the epidemiology and outcome of Barrett's oesophagus in Olmstead County, Minnesota. Gut 2001:48:304-9.

10 Li AGK, Fernandes E, Baird J, et al. Barrett's oesophagus is an independent risk factor in tumours of the upper gastrointestinal tract. Gut 2003;52(suppl 1):A48.

11 Cameron AJ, Lomboy CT. Barrett's esophagus: age, prevalence and extent of columnar epithelium. Gastroenterology 1992; 103:1241-5.

\section{BMJ}

3rd Asia Pacific Forum on Quality Improvement in Health Care

3-5 September 2003, Auckland, New Zealand

We are delighted to announce this forthcoming conference in Auckland, New Zealand.

The themes of the 3rd Asia Pacific Forum on Quality Improvement in Health Care are:

- Agenda for quality: Improving equity in health care delivery

- Improving safety

- Leadership for improvement

- Measuring quality and benchmarking for change

- Evidence based knowledge and education for quality improvement

- Improving health systems

- Patient/consumer centred quality improvement

Presented to you by the BM Publishing Group (London, UK) and Institute for Healthcare Improvement (Boston, USA), supported by the New Zealand Ministry of Health, ACC, and Standards New Zealand.

For more information about the Forum or to register contact: quality@bma.org.uk or go to:

www.quality.bmipg.com

Tel: +44(0)2073836409 Fax: +44(0)2073836869 